culturas y civilizaciones de la humanidad, anida básicamente en el campo de las cosmologías estético-religiosas. La respuesta mítica y ritual al conflicto interétnico es producto del choque de dos grandes civilizaciones, a partir del cual los vencidos sólo pueden ejercitar hermenéuticamente sólo jirones de la grandiosa trama intelectual creada y continuada hasta los días de la invasión hispana.

\title{
University of Pittsburgh.
}

JuAN ADOLFo VÁZQUEZ

Edelberto Torres, La dramática vida de Rubén Dario. Edición definitiva, corregida y ampliada. San José: Editorial Universitaria Centroamericana (Colección Rueda del Tiempo), 1980.

Desde 1952 la vida de Darío de Edelberto Torres se ha considerado como la mejor biografía del gran poeta. Su historia bibliográfica es la siguiente: primera edición, Guatemala: Editorial del Ministerio de Educación Pública, 1952; segunda y tercera edición, México: Grijalbo, 1956, 1958; cuarta edición, Barcelona: Grijalbo, 1966. Esta biografía aumenta mucho los datos de las ediciones anteriores y también tiene más de doscientas páginas de notas. Algunas reseñas criticaron a Torres la falta de documentación de las ediciones anteriores. El lector tuvo que poner mucha fe en lo que escribió Torres.

No es posible en el espacio de que dispongo comparar largamente esta nueva edición con la cuarta. Pero quiero hablar de las notas, novedad probatoria de esta edición.

Edelberto Torres es un erudito modesto y escribe en cuanto a sus notas lo siguiente: «Abundantes fueron los reclamos de universitarios distinguidos, para que pusiéramos notas indicadoras de las fuentes del texto. Ya hemos contestado esta objeción en introducciones anteriores. Nuestro trabajo no ha tenido intención erudita; quisimos ofrecer un libro de lectura fácil, amena en lo posible, y consideramos las notas contrarias a ese objetivo. Ahora hemos optado por algo difícil de lograr, que es complacer a los eruditos y a los lectores corrientes, poniendo notas al final de cada capítulo, que corresponden cada una a un pasaje del texto; pero sin numerarlas. Es posible que el orden riguroso se altere y aun haya alguna omisión» (p. 17).

No es posible satisfacer a los críticos. Hubiera preferido tener las notas con número para mejor hallarlas.

Las notas citan sus fuentes y reproducen documentos, cartas y artículos de periódicos. Algunas de ellas muestran los sentidos muy humanos del autor. Nota en la página 227 que Rubén Darío, III, escribió Los detractores de Rubén Dario «con la maligna intención de atacar a Francisca Sánchez y a los que han dicho algo o mucho de su vida con Rubén. Darío Basualdo se lanza contra ellos con una fobia que ninguna causa buena o mala, merecería, y pretendiendo combatirlos, lleva a cabo la más entristecedora detracción de Rubén Darío».

Se puede ver que las notas no son simples citas bibliográficas, sino que añaden mucho al texto. Publica también, de vez en cuando, cartas y otros documentos que muestran sus fuentes y aumentan nuestros conocimientos de la vida de Darío.

Las páginas 927-945 están dedicadas a una «Cronología de Rubén Darío»; de 946-948 registra los «Descendientes de Rubén Darío», y en 949-966 está la biblio- 
grafía activa y pasiva que consultó el señor Torres. La bibliografía muestra que Torres ha consultado todos los estudios publicados e inéditos más importantes que tratan de la vida y obra de Darío. Hay bastantes que no aparecen en la bibliografía porque en la "Introducción" Torres habla de las personas que él entrevistó, las bibliotecas y archivos en España y el Nuevo Mundo en que hizo sus investigaciones.

Una lista de erratas viene con el libro. La lista de «Suscriptores de honor» da mi nacionalidad como nicaragüense y en la página 327 nota que el libro de Alfred Ulner, Enrique Gómez Carrillo y el modernismo, San José: E.D. U.C.A., se publicó en 1976. Se llama Arnold Ulner. El libro de Ulner se publicó a finales de 1981. El interesado tiene que consultarlo en forma de microfilme. En la página 11 dice que solamente el primer tomo de Escritos dispersos de Rubén Dario se ha publicado. El segundo tomo tiene fecha de 1977. Falta un índice detallado de nombres propios y títulos.

Torres ha dedicado una gran parte de su vida al estudio de la vida de Darío y me es imposible hacer nada más que alabar sus esfuerzos eruditos. Su libro con sus notas y fotografías de Darío y sus amigos sigue como la mejor biografía del gran nicaragüense. Su estilo no permite que el lector deje el libro sin querer terminar su lectura cuanto antes. Además, quienes se interesan en la vida y obra de Darío han de sentir, sin duda, mucha gratitud por los esfuerzos de Torres para darnos un Darío muy humano.

Southern Illinois University-Carbondale.

HeNSLEY C. WOOdBRidge 